\title{
Forest Fire Risk Estimation in a Typical Temperate Forest in Northeastern China using the Canadian Forest Fire Weather Index, Case of Autumn 2019 and 2020
}

\author{
Maombi Mbusa Masinda \\ Northeast Forestry University \\ Fei Li \\ Northeast Forestry University \\ Qi Liu \\ Northeast Forestry University \\ Long Sun \\ Northeast Forestry University \\ Tongxin Hu ( $\square$ htxhtxapple@sina.com ) \\ Northeast Forestry University School of Forestry
}

\section{Research Article}

Keywords: fuel moisture content, weather, fire danger, Maoer mountain, forest ecosystems

Posted Date: May 7th, 2021

DOI: https://doi.org/10.21203/rs.3.rs-481816/v1

License: (c) (i) This work is licensed under a Creative Commons Attribution 4.0 International License. Read Full License

Version of Record: A version of this preprint was published at Natural Hazards on October 6th, 2021. See the published version at https://doi.org/10.1007/s11069-021-05054-4. 
Maombi Mbusa Masinda ${ }^{1,2}$, Fei Li $^{1}$, Liu Qi ${ }^{1}$, Long Sun ${ }^{1, *}$, Tongxin Hu ${ }^{1, *}$

\author{
${ }^{1}$ Key Laboratory of Sustainable Forest Ecosystem Management-Ministry of Education, College of Forestry, Northeast Forestry \\ University, 26 Hexing Road, Harbin 150040, China \\ ${ }^{2}$ Faculty of Sciences, Université Officielle de Ruwenzori, North Kivu, D.R. Congo \\ Correspondence and requests for materials should be addressed to Long Sun (sunlong365@126.com), Tel.: +86-139-4501-6458 \\ or Tongxin Hu (htxhtxapple@ sina.com), Tel.: +86-150-4608-9251. \\ *These authors contributed equally to this work.
}

\title{
Abstract
}

China's forest cover has increased by about $10 \%$ as a result of sustainable forest management since the late 1970s. The forest ecosystems area affected by fire is increasing at the alarming rate of roughly 600.000 ha per year. The northeastern part of China, with a forest cover of $41.6 \%$, has the greatest percentage of acres affected by forest fires. This study combines field and satellite weather data to determine factors that influence dead fuel moisture content (FMC). It assesses the use of the Canadian forest fire weather index (FWI) to determine the daily forest fire danger in a typical temperate forest in northeastern China in the fall season. Based on the Wilcoxon test for paired samples, the observed and predicted values of FMC showed similar variation in 63.6\% of sampling sites, with p-value > 0.05 ; and $36.4 \%$ of sampling sites presented lower predicted values of FMC than observed values, with $p$-value $<0.05$. The Canadian Forest Fire Danger Rating System estimated the fire danger level as very low, low, moderate, high, or very high in our Maoer mountain forest ecosystems.

Keywords: fuel moisture content, weather, fire danger, Maoer mountain, forest ecosystems

\section{Introduction}

Forest fires are the most widespread and critical disturbance in boreal and temperate forest ecosystems (Ying et al. 2018). While China's forest cover has increased by about 10\% as a result of sustainable forest management since the late 1970s (Nöchel and Svennin 2017), the forest area ecosystems affected by fire is increasing at the alarming rate of roughly 600 thousand hectares per year (Yang et al. 2010). Climatic conditions and forest composition in northeast China, much like those in the United States of America, Canada, Australia, and Mediterranean Europe, are favourable to forest fires. The northeastern part of China (Heilongjiang, Jilin, and Liaoning provinces), with a forest cover of $41.59 \%$, has the greatest percentage of acres affected by forest fires. Predictive climate models in China suggest that from 2041 to 2080, climate will be characterised by higher temperature (Wu et al. 2020). Accordingly, a high priority for forest protection in China is required (Thomas 1990), and there is an imperative need for China to develop its national forest fire danger rating system (Yang and Di 2011).

Wildfires are influenced by many factors, including vegetation, topography, weather, human behaviour, and ignition sources (Flannigan et al. 2005). Great labours have been made around the world to lower the effects of wildfire including fuel diminution and alteration, prescribed burning, and firebreak contour (Zong et al. 2021). However, it is particularly important to strengthen forest fire management and improve forest fire prediction capabilities in regions where the forest fire danger rating system remains to be developed. Ignition, spread and development of forest fires are strongly affected by the moisture content of forest fuels (Rothermel 1972; Dimitrakopoulos and Papaioannou 2001). In particular, the frequency of forest fires is directly affected by the 
moisture content of dead fuels on the ground. Therefore, accurately predicting the moisture content of dead fuels on the fore st surface is the key for forecasting forest fire risk and fire behaviour. Dead fine fuel moisture content varies both spatially and temporally as a function of microclimate and fuel properties (Cawson et al. 2020). Temperature, relative humidity, precipitation, wind velocity and solar radiation determine the moisture vapour differential between the dead fuel and atmosphere (Matthews 2014).

Aguado et al. (2007) have identified various methods estimating the FMC: the field sampling, standard fuels and meteorological indices. Prediction model of fuel moisture content by the gravimetric method is often considered as the gold standard approach (Matthews 2010). Nevertheless, this approach has limited use as it cannot provide continuous or real-time moisture data when desired and needs continuous equipment and workers in the field (Cawson et al. 2020). The method that used standard fuels is based on monitoring weight changes of previously calibrated surface forest fuels that are presumed to be good representatives of certain fuel sizes. It reduces the effort of field sampling and provides an instant estimation of FMC. However, this method has a little spatial significance as the measurements are limited (Aguado et al. 2007). Meteorological danger indices method is often used to measure dead FMC. These indices depend on present and past meteorological conditions, since they try to evaluate the drought of different forest fuels. It leads to frequent updating and, in addition to estimating FMC, offers other critical variables for fire management. Based on the last method, this study used the FMC meter to evaluate the change of the FMC as it instantly evaluate the change of FMC in any place; however il also needs manual measurement before or after the experiment (Masinda et al. 2021).

Prediction of forest fire has been studied for decades using different forest rating systems like the Canadian Forest Fire Danger Rating System (CFFDRS), U.S. Forest Service National Fire Danger Rating System (NFDRS), and McArthur Forest Fire Danger Index -FFDI- (Di Giuseppe et al. 2016). Although a wide range of indices has been developed to calculate fire risk (Bett et al. 2020), many are limited to specific areas while some indices are valid on a large scale like the fire weather index (FWI). The CFFDRS has, since the early $20^{\text {th }}$ century, involved an extensive network of weather observations, FMC field sampling, and ignition sustainability investigations (Fujioka et al. 2008). The FWI system is a sub-system of the CFFDRS (de Groot and Groot 1987). The FWI was established by Van Wagner (1974) and is more efficient than other forest fire indices (Schunk et al. 2017; Tremblay et al. 2018). It predicts the FMC by relying on meteorological variables from different global regions. It then combines these variables to analyse fire behaviour in terms of spread and intensity (Vitolo et al. 2019). It also determines the effects of meteorological variables on forest fuels and forest fires by providing a relative numerical rating of fire danger over a given area. However, it is not able to describe a complete picture of daily wildfire danger with a single number (Stocks et al. 1989).

Initially developed for use in Canadian pine stands, FWI sees widespread use in other forest stands due to its simplicity of fit. The FWI system is widely approved by many fire and land management agencies, which use it to issue fire warnings and assign resources in the field (Dimitrakopoulos et al. 2011; Vitolo et al. 2019), but it only offers a qualitative overview of predicted fire regimes. Many studies have established a strong relationship between FWI codes/indices and fire occurrence and behaviour (Papagiannaki et al. 2020). Simpson et al. (2014) argued the necessity of evaluating the suitability of applying the FWI system to regions other than the one in which it was originally established. Accordingly, this work attempted to provide insights on the following questions: Which weather variables influenced much the fuel moisture content in Maoer mountain forest ecosystem? Does the relationship between the moisture of the FMC meter and China Weather Satellite Station (CWSS) change by forest type and time? What is the rating of fire danger in the fall fire-prone season? Thus, it aimed to determine the main meteorological factors influencing FMC in a typical temperate forest in northeastern China and to assess the potential use of the Canadian Forest Fire Weather Index as a decision-support tool in fire hazard management. 


\subsection{Study location}

This study was conducted in a typical temperate forest of Maoer mountain, in northeastern China $\left(45^{\circ} 43^{\prime} \mathrm{N}, 126^{\circ} 37^{\prime} \mathrm{E}\right.$; average elevation is $255 \mathrm{~m}$ ). The surface area of Maoer mountain forest ecosystem is 21813.1 ha. The region features a cold, temperate climate, with rainy summers. It receives an average annual rainfall of $649 \mathrm{~mm}$. The hottest month in this area is July, with an average temperature of $21.8^{\circ} \mathrm{C}$, while January is the coldest month with an average temperature of $-19.9^{\circ} \mathrm{C}$. The annual thermal amplitude is $41.7^{\circ} \mathrm{C}$ and the rainfall amplitude is $171 \mathrm{~mm}$. The bedrock is granite and the soil is mainly dark brown forest soil (Wang 2006). Since the beginning of the $20^{\text {th }}$ century, the primary forest has been gradually degraded by large-scale industrial logging by Russian and Japanese invaders as well as by the Chinese government. The primary forest, which was dominated by Pinus koraiensis Siebold and Zucc. mixed with deciduous species such as Betula platyphylla Sukaczev, Larix gmelinii L., Populus davidiana Dode, Quercus mongolica Fisch., and Fraxinus mandshurica Rupr., has been replaced by a secondary forest and mostly by L. gmelinii plantations (Chen et al. 1982). Currently, there are three main types of secondary forest distributed in various sites characterised by different conditions. These forests are forest of Quercus mongolica on steep upper slope arid and infertile, the mixed deciduous forest located at well-drained fertile gentle mid-slope and the deciduous forest on gentle slope moist, and fertile. There are also two dominant plantations: L. gmelinii and P. koraiensis plantations (Wang 2006). In the winter, the temperature is low, the snow is frozen, and there are no burning conditions, so forest fires are registered during these periods. The mean annual area of burnt forest in Heilongjiang Province varies between 500 and $2500 \mathrm{~km}^{2}$ ( $\mathrm{Li}$ et al. 2015). These averages represent 0.25 $1.2 \%$ of the total forest cover $\left(205,328 \mathrm{~km}^{2}\right)$ of Heilongjiang Province estimated as in the China forest administration website (12 December 2019).

\subsection{Meteorological data acquisition and use}

This study used data from FMC meters which provide measurements of meteorological variables and the fresh weight of fuel on the ground surface (Masinda et al. 2021). It also used data from the CWSS as the installation of FMC meters over large areas of forest requires a lot of resources (material, financial, temporal and human). The first series of data was acquired from the FMC meters in the field. FMC meters were set in Maoer mountain forest ecosystem to track the change of dead fuel moisture content in relation to variations in air temperature, relative humidity, solar radiation, wind speed, and rainfall. We acquired the second series of data from the CWSS -Harbin Station- (http://cdc.cma.gov.cn/, station id: 50953, $45.45^{\circ} \mathrm{N}$ and $126.46^{\circ} \mathrm{E}$ ), which included temperature, relative humidity, wind speed and total daily rainfall. The temporal and spatial resolution of CWSS are respectively one hour and seventy-one kilometres. These series of data served to develop the FMC patterns and to calculate the FWI indices (noon temperature, relative humidity, wind speed, and total daily rainfall).

\subsection{Sampling}

It is rarely practical to measure the dead fuel moisture content directly in the field; thus, it is generally estimated. It is possible to use either real or predicted values of air relative humidity and temperature to reasonably estimate the FMC (De Melo-Abreu et al. 2010). In this study, we used the FMC meter which is a device consisting of an automatic balance and a mini weather station. It automatically measures the fresh fuel mass, air temperature, relative humidity, wind speed, solar radiation, and rainfall reaching the fuels on the ground surface (as well as soil moisture and temperature) at an instantaneous time interval. It supplies a continuous and automated measurement of the FMC that can be transferred from remote sampling site, reducing the manpower required to get information on the variation of the moisture content in the field. 
Data were collected at 11 sampling points (5 and 6 sampling plots in 2019 and 2020, respectively) arranged on four linear transects (Table 1). Transects were separated by $1.11 \mathrm{~km}$, or 0.01 degree of latitude and sampling points on each transect were distant one of the other of $0.788 \mathrm{~km}$, corresponding to 0.01 degree of longitude at 45 degree of latitude. Around each sampling point, we had plotted a quadrant of 50 meters side which was used to describe the vegetation around it. In each quadrant, we manually gathered samples of dead fine surface fuels over an area of $30 \mathrm{~cm} \times 30 \mathrm{~cm}$ along the transect, equivalent of the FMC basket meter. Samples were composed of twigs of one hour time-lag and freshly fallen nonwoody material which includes leaves, cones, pollen cones (Keane 2015). We then oven-dried our samples at $105^{\circ} \mathrm{C}$ for 24 hours and determined the moisture content as the fraction of water mass $\left(W_{f}\right)$ to oven-dry fuel mass $\left(W_{d}\right)$ :

To estimate the moisture content of fine dead fuel using the FWI system (Wotton 2009), we deduced the predicted values of the FMC using the Fine Fuel Moisture Code (FFMC) according to the following formula:

Table 1 Local field sampling characteristics

126 In this table, D denotes the depression while TH represents the tree height.

\begin{tabular}{|c|c|c|c|c|c|c|c|}
\hline Site & Longitude & Latitude & Tree species composition & Aspect & Slope & $\mathrm{D}$ & $\mathrm{TH}$ \\
\hline 1 & 127.65 & 45.40 & $\begin{array}{l}\text { Betula platyphylla Sukaczev, Populus davidiana Dode and Fraxinus } \\
\text { mandshurica Rupr. }\end{array}$ & North & 15 & 0.7 & 18 \\
\hline 2 & 127.69 & 45.41 & $\begin{array}{l}\text { Betula platyphylla, Populus davidiana, Tilia mandshurica Rupr. and } \\
\text { Maxim. and Juglans mandshurica Maxim. }\end{array}$ & West & 10 & 0.8 & 17 \\
\hline 3 & 127.66 & 45.41 & $\begin{array}{l}\text { Fraxinus mandshurica, Juglans mandshurica, Phellodendron } \\
\text { amurense Rupr., and Ulmus pumila L. }\end{array}$ & Northwest & 15 & 0.7 & 16 \\
\hline 4 & 127.67 & 45.41 & $\begin{array}{l}\text { Fraxinus mandshurica, Juglans mandshurica, Tilia mandshurica, } \\
\text { Populus davidiana, Betula costata Trautv, Ulmus pumila, etc. }\end{array}$ & Northwest & 15 & 0.6 & 17 \\
\hline 5 & 127.68 & 45.41 & $\begin{array}{l}\text { Populus davidiana, Tilia mandshurica, Juglans mandshurica, Betula } \\
\text { costata and Fraxinus mandshurica }\end{array}$ & Southeast & 15 & 0.8 & 18 \\
\hline 6 & 127.67 & 45.43 & $\begin{array}{l}\text { Fraxinus mandshurica, Juglans mandshurica, Phellodendron } \\
\text { amurense Rupr., Betula platyphylla }\end{array}$ & North & 14 & 0.7 & 17 \\
\hline 7 & 127.66 & 45.42 & Larix gmelinii and Ulmus propinqua & Southeast & 10 & 0.7 & 18 \\
\hline 8 & 127.66 & 45.40 & Quercus mongolica Fisch. and Ledeb. & South & 11 & 0.8 & 14 \\
\hline 9 & 127.70 & 45.41 & Pinus sylvestris, Betula platyphylla and Ulmus propinqua & Southeast & 9 & 0.6 & 15 \\
\hline 10 & 127.67 & 45.41 & Ulmus propinqua, Juglans mandshurica, Quercus mongolica & Northeast & 12 & 0.7 & 16 \\
\hline 11 & 127.67 & 45.42 & Ulmus propinqua, Fraxinus mandshurica, Phellodendron amurense & Northwest & 13 & 0.8 & 17 \\
\hline
\end{tabular}

To assess the FMC variation, we fitted general linear models to select variables that have a strong effect on FMC. The FMC meter dataset consisted of air temperature, relative humidity, wind velocity, solar radiation and fresh fuel weight. The CWSS dataset included the temperature on the ground surface, temperature at 10 meters height, sunshine-hours, relative humidity, rainfall and wind velocity. Before computed FMC models, variable importance was first determined using the random forest method and was presented by a graph. Collinearity was checked for each model; thus, FMC models were developed. All models were computed in RStudio version 1.1.453.0 (RStudio Inc. 2018) and fuel moisture content variation was drawn with 
136

137

138

139

140

141

142

143

144

Estimation of FWI indices and codes was obtained using fwi-function with the cffdrs-R package (RStudio Team 2018; Integrated Development for RStudio, Inc., Boston, MA) based on noon local standard time weather observations, including temperature, relative humidity, wind speed, 24-hour rainfall, and the previous day's fuel moisture conditions (Wang et al. 2019). These codes and indices are respectively the fine fuel moisture code (FFMC), duff moisture code (DMC), drought code (DC), build-up index (BUI), and initial spread index (ISI). The daily severity rating (DSR) is an additional component of the FWI system, planned to be more directly related to the probable effort required for wildfire suppression, and it is a power conversion of FWI that underlines high FWI values (Tsinko et al. 2018). We used the qualitative Forest Fire Danger Rating System as established by Van Wagner (1987) to describe the fire danger as very low, low, moderate, high, very high, or extreme (Table 2).

Table 2 Fire danger rating scale

\begin{tabular}{lc}
\hline Danger classes & FWI range \\
\hline Very low & $00-01$ \\
Low & $02-04$ \\
Moderate & $05-08$ \\
High & $09-16$ \\
Very high & $17-29$ \\
Extreme & $30+$ \\
\hline
\end{tabular}

145

\section{Results}

\subsection{Response of FMC variation to weather factors}

147

Our results showed that, relatively, the FMC was more sensitive to rain, less sensitive to relative humidity and temperature, and insensitive to wind speed (Fig. 1- a, b). In addition, the FMC response to a rainfall of 2 - 4 mm during a good drying day took 2-3 days for the FMC to recover the pre-rain values. These results highlight the strength of the relationship between rain and FMC variation.
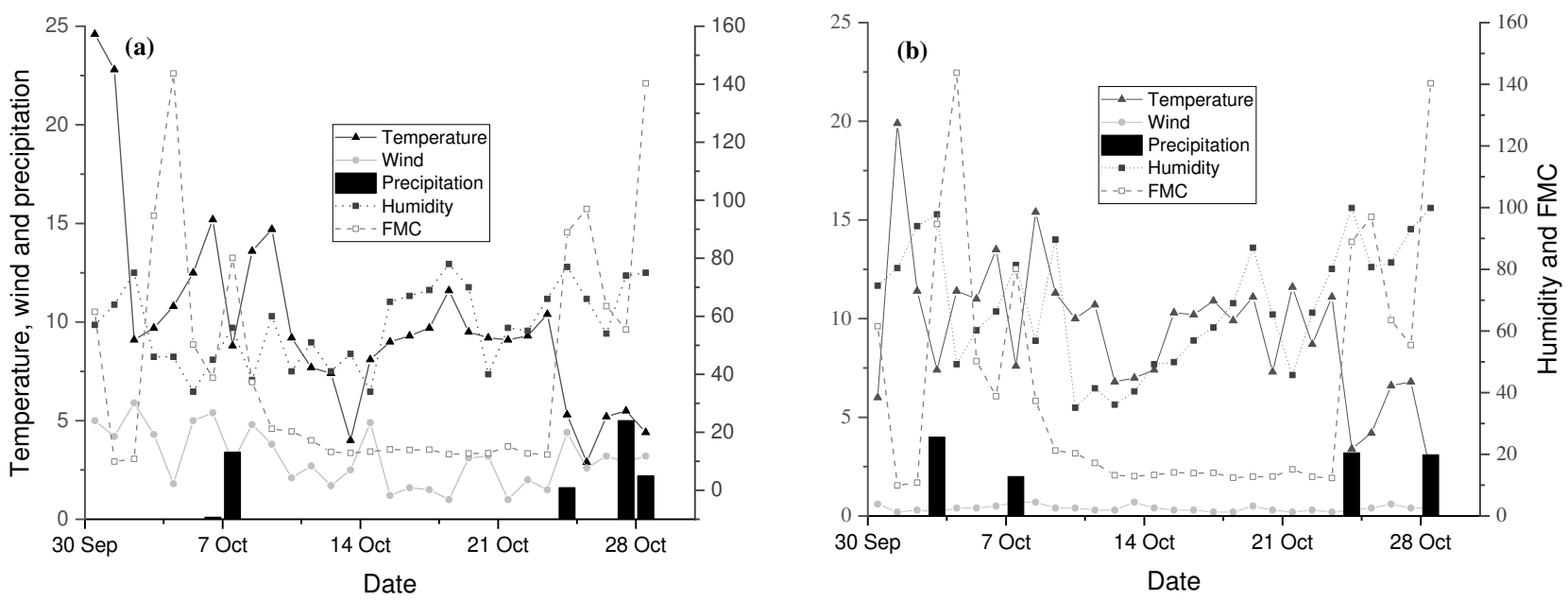

Fig. 1 Variation of FMC based on (a) FMC meter and (b) China Weather Station database 

other hand, the first and the last week of the month presented high values of FMC, mainly due to rain. In 2020, results in Fig. 3a, b, c, d, e, f showed that the predicted (FMC meter and CWSS) FMC varied at the same rate as the measured FMC although, a dizzying increase in FMC was observed after the rain of October 20. The maximum value of FMC approached 325\% (Fig. 3-e) while the minimum FMC value was $7.4 \%$ (Fig. 3-b).

160
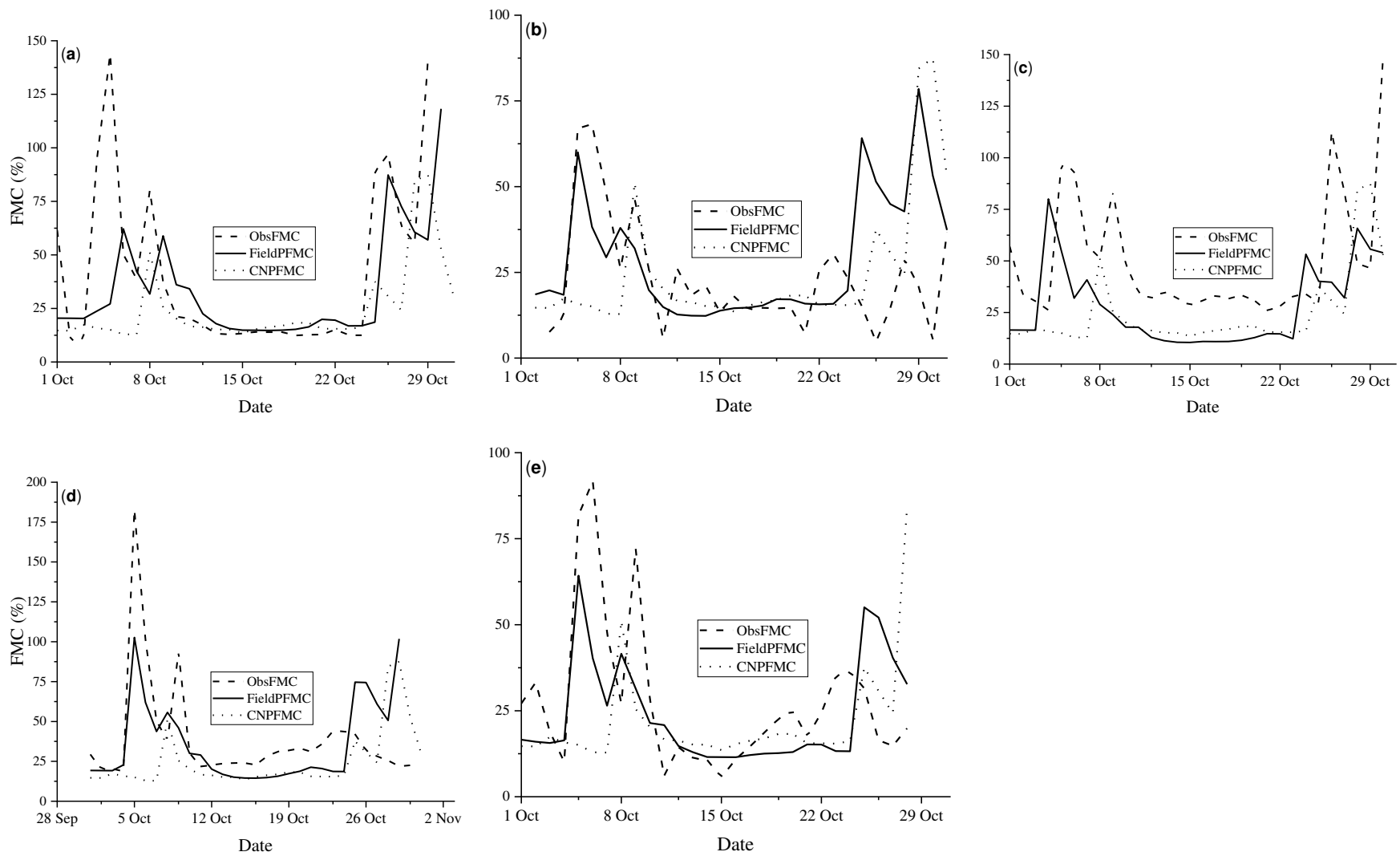

161

162

Fig. 2-a, b, c, d, e Observed versus FMC meter and CWS predicted FMC, in 2019
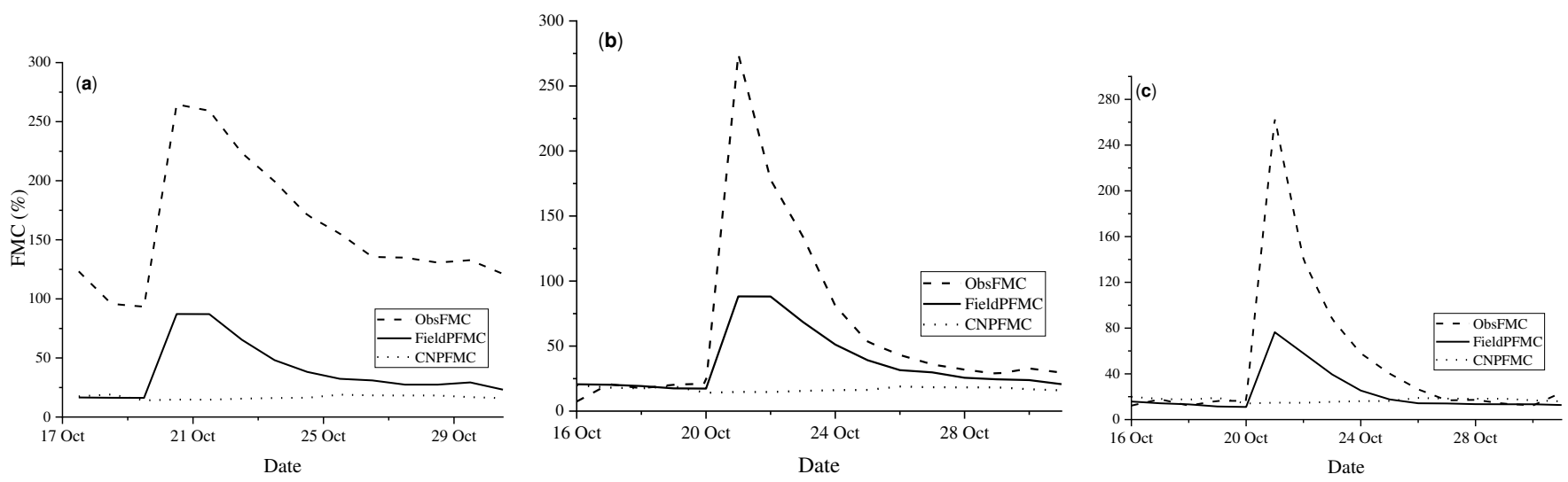

163 

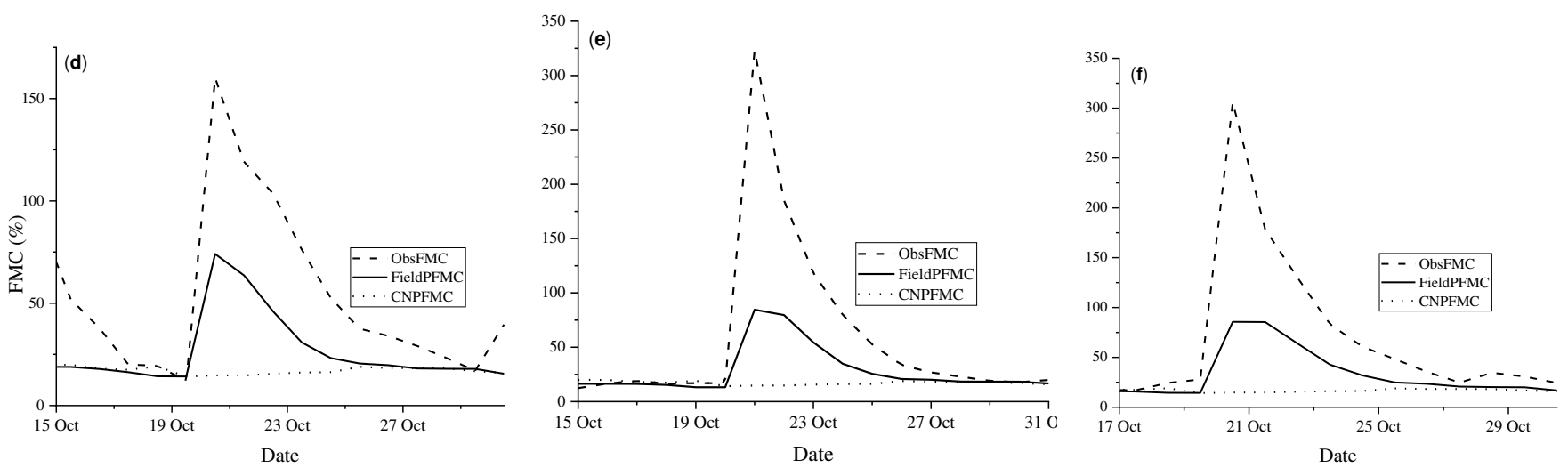

164

165

166

167

168

169

170

171

172

173

174

175

176

177

178

179

180

181

182

183

184

185

Fig. 3-a, b, c, d, e, f Observed versus FMC meter and CWSS predicted FMC, in 2020

\subsection{Patterns of fuel moisture content}

\subsubsection{Predicted model with both data sources}

The general linear model developed with both FMC meter and CWSS variables showed that rain and relative humidity influence on FMC were strong than the influence of temperature, wind speed, solar radiation and sunshine time. All models presented a good predive power (R-sq. adj.) > 70). In the fitted models (Table 3), $T, H, W, R n$, and $R$ respectively denote the temperature, relative humidity, wind speed, rain and solar radiation from the FMC meter and $S S$ the sunshine timing and $T_{h}$ the temperature at $2 \mathrm{~m}$ height for the CWSS data source. The residual standard error (RSE) varied from 15.72 to 31.17; the F-statistic varied between 34.28 and 74.15 while the degree of freedom (DF) oscillated between 26 and 29.

Table 3 FMC models fitted with FMC meter and CWSS data

\begin{tabular}{llllll}
\hline Model & Equation & RSE & R-sq. (adj.) & F & DF \\
\hline 1 & $F M C=25.29 R n+3.77 S S$ & 31.17 & 0.70 & 34.28 & 27 \\
2 & $F M C=2.989 S S$ & 15.72 & 0.71 & 74.15 & 29 \\
3 & $F M C=1.165 H-4.536 T+0.180 R$ & 20.19 & 0.88 & 73.56 & 27 \\
4 & $F M C=0.491 H+0.130 \mathrm{Rn}^{5}$ & 26.73 & 0.72 & 40.39 & 28 \\
5 & $F M C=2.647 T_{h}+0.235 R^{4}$ & 17.26 & 0.76 & 44.20 & 26 \\
\hline
\end{tabular}

\subsubsection{Predicted model with FMC meter data}

Apart from developed models in the above section, we computed daily and diurnal models of FMC in order to observe if the effect of sun would increase the quality of the model. Thus, in each site FMC models were developed in 2019 and 2020 with diurnal or daily data.

Developed models in 2019 showed that relative humidity, temperature, wind speed and solar radiation influenced the water content of fuels in site 1. In site 2, humidity, temperature and wind speed are the influential factors. In sites 3, 4 and 5, wind speed and rain did not result in a substantial improvement in model efficiency. A general overview on daily developed FMC models proved that relative humidity, temperature, solar radiation and wind velocity influenced much the FMC. The integration of rain ( $p$-value $>0.05$ ) did not result in a substantial improvement in model efficiency. Out of five sampling sites, one was characterised by a high predictive power model: R-sq.(adj.) $=0.70$. The other four sites were characterised by models with medium predictive power: $0.52 \leq$ R-sq.(adj.) $\leq 0.64$ (Table 4 ). 
Developed models with diurnal data showed that relative humidity, temperature and solar radiation had a strong effect on FMC. The influence of wind velocity and rain were not noticeable. Results in Table 5 showed that sites 1, 2 and 3 were characterised by models with high predictive power: $0.72 \leq \mathrm{R}$-sq.(adj.) $\leq 0.80$ while sites 4 and 5 were characterised by models with medium predictive power: $0.50 \leq \mathrm{R}$-sq.(adj.) $\leq 0.55$. The residual standard error is RSE oscillated between 0.35 and 34.97 for daily developed models and 0.29 to 31.71 for diurnal developed models in Table 4. The F-statistic varied between 337.6 to $787.6(773 \leq \mathrm{DF} \leq 1016)$ for daily fitted models and F-statistic shifted between 138.3 and $664.1(408 \leq \mathrm{DF} \leq 540)$, etc.

Daily developed models of FMC in 2020 indicated that relative humidity, rain and temperature were the most important 193 factors influencing the water content of fuels in all sampling sites. The effect of wind on water content was significant in site 1 and the effect of solar radiation was only influential in site 3. Two of six sampling sites were characterised by models with high predictive power: $0.73 \leq \mathrm{R}$-sq.(adj.) $\leq 0.83$. The other four sites were characterised by models in medium predictive power: 0.52 $\leq$ R-sq.(adj.) $\leq 0.66$ (Table 6). In addition, developed models with diurnal data showed that relative humidity, temperature and rain were the influencing drivers of FMC. Three sites were characterised with models in high predictive power, R-sq.(adj.) $>0.70$ and three others with medium predictive power: $0.61 \leq$ R-sq.(adj.) $\leq 0.66$ (Table 7).

199 Table 4 Daily developed FMC models in 2019

\begin{tabular}{llllll}
\hline Model & Equation & RSE & R-sq.(adj.) & F & DF \\
\hline 1 & $F M C=0.648 H-2.491 T+30.119 W+0.043 R$ & 34.97 & 0.64 & 343.3 & 773 \\
2 & $F M C=0.130 H+1.241 T+1.543 \mathrm{~W}$ & 17.12 & 0.57 & 427.5 & 984 \\
3 & $F M C=0.008 H-0.007 T+0.0004 R$ & 0.35 & 0.70 & 678.3 & 880 \\
4 & $F M C=0.347 H+0.003 R$ & 25.27 & 0.61 & 787.6 & 1016 \\
5 & $F M C=0.237 H+1.243 T+0.001 R$ & 24.21 & 0.52 & 337.6 & 943 \\
\hline
\end{tabular}

Table 5 Diurnal developed FMC models in 2019

\begin{tabular}{llllll}
\hline Model & Equation & RSE & R-sq.(adj.) & F & DF \\
\hline 1 & $F M C=0.979 H-1.735 T$ & 31.71 & 0.72 & 599.9 & 469 \\
2 & $F M C=0.134 H-0.156 T^{2}+4.915 T-0.029 T \cdot H$ & 15.38 & 0.72 & 277.4 & 423 \\
3 & $F M C=0.013 H-0.010 T+0.00023 R$ & 0.29 & 0.80 & 664.1 & 496 \\
4 & $F M C=0.456 H+0.019 R$ & 31.68 & 0.55 & 334.9 & 540 \\
5 & $F M C=0.481 H+2.620 T-0.046 T \cdot H$ & 29.85 & 0.50 & 138.3 & 408 \\
\hline
\end{tabular}

Table 6 Daily developed FMC models in 2020

\begin{tabular}{llllll}
\hline Model & Equation & RSE & R sq.(adj.) & F & DF \\
\hline 1 & $F M C=1.982 H-2.499 T+59.368 W+85.949 R n$ & 87.97 & 0.83 & 848.4 & 692 \\
2 & $F M C=0.808 H-1.132 T^{2}+54.249 R n^{2}$ & 55.06 & 0.63 & 420.0 & 741 \\
3 & $F M C=0.882 H-2.968 T+46.989 R n+0.044 T \cdot H$ & 42.56 & 0.65 & 402.1 & 857 \\
4 & $F M C=0.722 H+22.438 R n$ & 35.18 & 0.73 & 1220.0 & 886 \\
5 & $F M C=0.952 H^{2}+64.02 R n$ & 81.29 & 0.52 & 550.2 & 1007 \\
6 & $F M C=0.830 H+54.805 R n$ & 55.52 & 0.66 & 715.8 & 740 \\
\hline
\end{tabular}


Table 7 Diurnal developed FMC models in 2020

\begin{tabular}{llllll}
\hline Model & Equation & RSE & R sq.(adj.) & F & DF \\
\hline 1 & $F M C=2.288 H-2.866 T$ & 82.41 & 0.82 & 529.3 & 230 \\
2 & $F M C=1.164 H-3.647 T+48.114 R n$ & 53.25 & 0.64 & 151.3 & 251 \\
3 & $F M C=1.165 H-7.686 T+0.159 T \cdot H$ & 38.07 & 0.74 & 245.9 & 260 \\
4 & $F M C=0.959 H-1.102 T^{2}$ & 33.74 & 0.76 & 475.4 & 301 \\
5 & $F M C=1.257 H-3.757 T+62.70 R n$ & 58.67 & 0.61 & 143.4 & 272 \\
6 & $F M C=1.219 H-2.260 T+46.572 R n$ & 55.05 & 0.66 & 162.3 & 245 \\
\hline
\end{tabular}

203

204

205

206

207

208

209

210

211

3.4. Adequacy of the FWI system in predicting the FMC in Maoer mountain forest ecosystem

The Wilcoxon test for paired samples showed that the observed and predicted values of FMC in 2019 were similar in sites 1, 2 , and 5 ( $p$-value $>0.05)$ and different in sites 3 and 4 (p-value $<0.05)$. Note that the predicted FMC values were calculated with the FWI function. In 2020, the Wilcoxon test for paired samples showed that the moisture content predicted with FMC meter data were significantly different to the moisture content predicted with CWS data in sites 1, 2 and 6 ( $p$-value < 0.05). In sites 3, 4 and 5 , both moisture contents were similar ( $p$-value $>0.05$ ). The difference between the observed and estimated FMC in site 1, 4 and 6 would be influenced by canopy density, altitude, slope, aspect or may be related to sampling facts rather than to real variance in moisture content (Table 8).

Table 8 Wilcoxon's test result for paired samples between the observed and predicted FMC

\begin{tabular}{llllll}
\hline Sites & Estimated parameter $(\boldsymbol{V})$ & $\boldsymbol{p}$-value & Sites & Estimated parameter $(\boldsymbol{V})$ & $p$-value \\
\hline $\mathbf{1}$ & 248 & $>0.05$ & $\mathbf{1}$ & 101 & $<0.001$ \\
$\mathbf{2}$ & 206 & $>0.05$ & $\mathbf{2}$ & 134 & $<0.001$ \\
$\mathbf{3}$ & 465 & $<0.001$ & $\mathbf{3}$ & 59 & $>0.05$ \\
$\mathbf{4}$ & 129 & $>0.05$ & $\mathbf{4}$ & 109 & $>0.05$ \\
$\mathbf{5}$ & 122 & $>0.05$ & $\mathbf{5}$ & 100.5 & $>0.05$ \\
$\mathbf{-}$ & - & - & $\mathbf{6}$ & 105 & $<0.05$ \\
\hline
\end{tabular}

212

213

214

215

216

217

218

219

\subsection{Fire danger estimation}

The value of FWI varied across the study period (October 2019) was low from October $1^{\text {st }}-12^{\text {th }}$, moderate from October $13^{\text {th }}$ $18^{\text {th }}$, very high from October $19^{\text {th }}-26^{\text {th }}$, and low from October $26^{\text {th }}-31^{\text {st }}$. It had rained only during the first and last week of the study period. The lack of rain was mainly responsible for the high fire danger ratings. Fig. 4-a depicts that the FWI values in sites 2 and 3 from October $21^{\text {st }}-25^{\text {th }}$ reached a high or a very high level of fire danger, while FWI values in sites 1,4 , and 5 varied between the very low and the moderate fire danger level. Results in Fig. 4-b illustrate that from 14 to 31 October 2020, the FWI oscillated between 0 and 5.56. Unfortunately, the value of FWI from 14 to 31 October in 2020 was lower than in 2019 in the same time interval. 

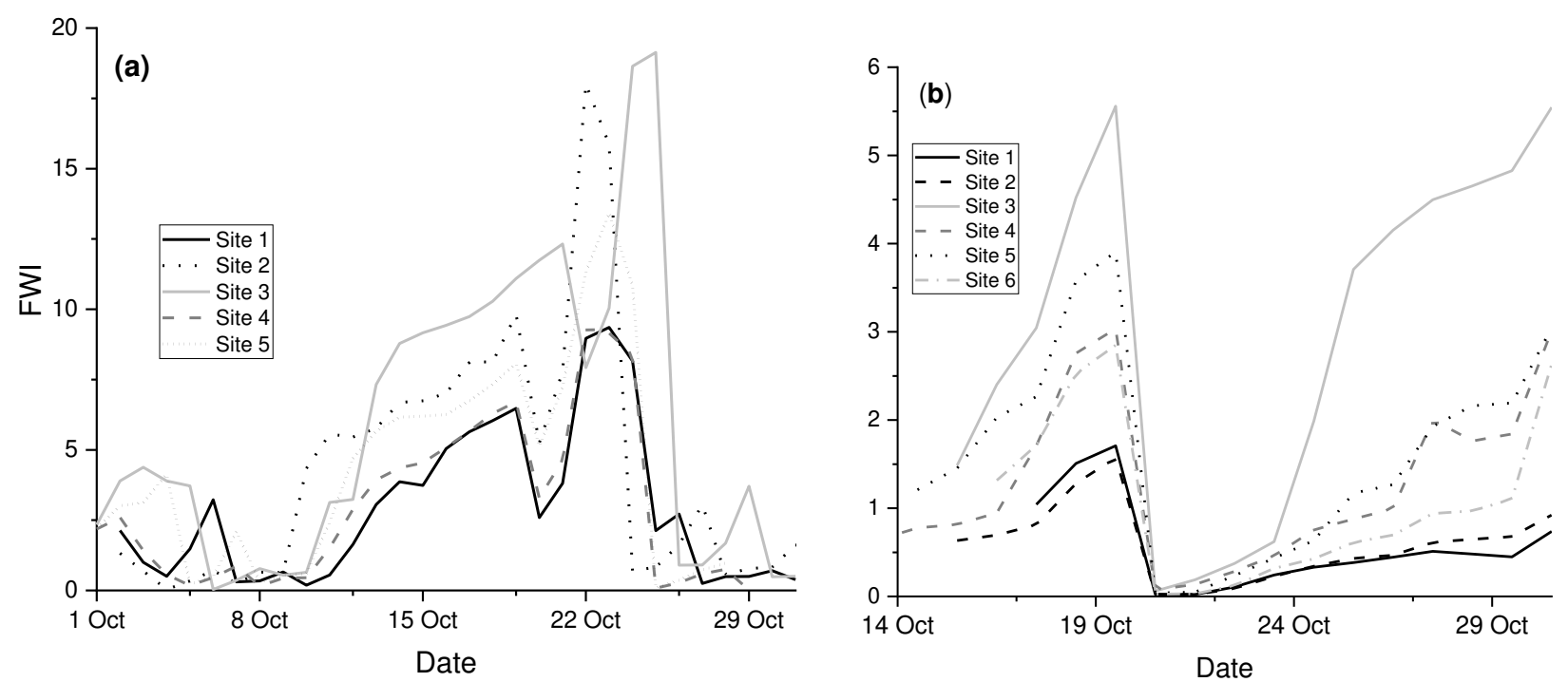

220

Fig. 4 Variation of FWI in 2019 (a) and 2020 (b)

222

223

224

225

226

227

228

229

230

231

232

233

234

235

236

237

238

239

240

241

242

243

\section{Discussion}

In this paper, we analysed the FMC variation and fire danger in typical temperate forests in order to (i) identify the most important variables affecting FMC changes and (ii) evaluate the skill of the FWI system in predicting forest fire risk in temperate forest stands, in northeastern China.

\subsection{FMC changes}

There were weighty increases in FMC during rainfall (Fig. 1- a, b). Although there were some divergences in FMC presentation, all data sources displayed similar FMC changes and provided the same information to researchers and fire managers. The difference between field $\left(45.41^{\circ} \mathrm{N}, 127.67^{\circ} \mathrm{E}\right)$ measures and those obtained from CWSS $\left(45.45^{\circ} \mathrm{N}, 126.46^{\circ} \mathrm{E}\right)$ is presumably related to the distance between the station and the experimental area. Thus, an increase in number of weather stations in fireprone regions is needed as suggested by Chuvieco et al. (1999, 2002) and Zhang et al. (2011).

The FWI system underestimated the FMC values, compared to field-experimental observations (Fig. 2 and 3). The disparity between observed and predicted values may be a result of the height at which wind speed was sampled, which differed between the field measurements and the estimated values. Tree canopy may also play a role in this difference. We measured temperature and wind speed at $0.3 \mathrm{~m}$ above the ground under tree cover, while the FWI system measures temperature at $2 \mathrm{~m}$ and wind speed at $10 \mathrm{~m}$ in an open area (Field 2020). Accordingly, previous studies have shown that tree canopy reduces solar radiation and wind flow on the ground surface and has an effect on dead fuel moisture content (Zylstra 2011; Estes et al. 2012; Zhang et al. 2017).

\subsection{FMC meter data prediction}

Different sites revealed variability in the accuracy of FMC predictors. Relative humidity, temperature and/or solar radiation had a significant effect on FMC in these sites. Diurnal models were more accurate than daily models, however FMC drivers were the same in both models. After a 2 - $4 \mathrm{~mm}$ rainfall, the FMC needed 2 - 3 days to recover its pre-rainfall values. Thus, we hypothesised that firefighters could spend two to three days without raids in the field as dead fuels would be too wet to burn for approximately two to three days after the rainfall event. During this period, the fuel water content exceeded the ignition and fire 
spread threshold of all types of fuel in the region (Masinda et al. 2020). Comparison between observed and predicted FMC showed that the observed values were slightly greater than the predicted values but were not significantly different (Table 8). Results of 2019 and 2020 allowed us to adopt the use of both data sources to predict the moisture content of dead fine surface fuels in Maoer mountain forest ecosystem because at eleven sampling sites, the predictions were statistically similar in seven sites, i.e. $63.6 \%$.

\subsection{Validity of the FWI system for fire risk management in typical temperate forests in China}

Our FWI values were similar to those of other Chinese provinces where the FWI values were linked to fire (Lynham and Stocks 1989; Tian et al. 2011, 2014; Yang and Di 2011). More studies had found a strong relationship between FWI and wildfire occurrence in other regions, like the Mediterranean, south-east and Central Europe (Good et al. 2008; Dimitrakopoulos et al. 2011; De Jong et al. 2016; Bedia et al. 2018; Lahaye et al. 2018; Fernandes 2019), Russia (Tosic et al. 2019), Australia (Dowdy et al. 2010), and on the global scale (Field et al. 2015). Our results showed that the FWI value in the interval from October 21 to 28 exceeded 13.95 and approached 20.67, which corresponds to more than 30 and 170 ha of burnt forest, respectively, according to Xanthopoulos et al. (2014) scale. The FWI system has produced valuable insight for fire management by determined very low, low, medium, high and very high level of fire danger in Maoer mountain forest ecosystem. It improves the accuracy of fire hazard assessment in the study area by informing the public of imminent fire hazards; thus, it is a useful tool to regulate access to forest ecosystems during the fire-prone season.

The spatial distribution of FWI indices differs considerably across the globe. Although FWI values can be calculated at any location based on weather variables, however, they are only useful where fuels are available (Vitolo et al. 2019). Considering the heterogeneity of forest ecosystems and the uncertainty of future trends in fire severity and intensity, which is largely due to complex, non-linear interactions among weather, forest, and anthropogenic factors, specific information about vegetation type vulnerability is needed on both local and global scales (Flannigan et al. 2009; Papakosta and Straub 2017; Fernandes 2019).

\subsection{Implication for wildfire management}

The FMC meters serve to track the moisture content of dead fuel over time in a range of landscape locations without the need of frequent study area visits. They are more precise than distant weather stations, particularly in different locations with different forest ecosystems. However, they should be used in concert with other tools as sometimes they can't track data when their batteries are discharged. Many humidity models used by fire managers had been established with data from weather stations remote from sampling sites, so FMC meters are valuable in this regard. The challenge we have is to equip the FMC meter with all its components necessary to collect all the useful data, even remotely.

\section{Conclusion}

This study evaluates the aptitude of the Canadian Forest Fire Weather Index in estimating fire danger in typical temperate forest stands in the northeast of China. Before evaluation, we developed FMC models with FMC meter and CWSS data. From this dataset, we determined the most important weather variables responsible for changes in fuel moisture content. FMC meter data were more accurate in estimating fire danger than CWSS data, suggesting more local meteorological stations in fire-prone regions would be beneficial in fire-risk assessment. In four of five models, rain had the strong effect on the variation of FMC. Relative humidity, temperature, and solar radiation also had a relative effect on FMC. Among models built from field data, there was variation in factors affecting FMC. Relative humidity was the most important factor, followed by radiation, temperature, and 
rainfall. The Canadian Forest Fire Danger Rating System estimated the fire danger level as very low, low, moderate, high, or very high in our Maoer mountain forest ecosystems.

\section{Acknowledgments:}

We sincerely thank Professor Wang Chuankuan, Director of the Global Ecology Laboratory at Northeast Forestry University for providing us rainfall data. We also thank Ms. Zhang Yujing for her collaboration. We would like to thank Elizabeth Tokarz of Yale University and Chula Mwagona Patteson for their assistance with spell checking and grammar editing.

\section{Funding}

This work was carried out within the framework of the National Key Research and Development Program of China, Key Projects for Strategic International Innovative Cooperation in Science and Technology (2018YFE0207800) and was partly sponsored by the China Scholarship Council (CSC No.2016DFH417).

Competing interests: The authors declare there are no competing interests.

\section{References}

Bedia J, Golding N, Casanueva A, et al (2018) Seasonal predictions of Fire Weather Index: Paving the way for their operational applicability in Mediterranean Europe. 9:101-110. https://doi.org/10.1016/j.cliser.2017.04.001

Bett PE, Williams KE, Burton C, et al (2020) Skillful seasonal prediction of key carbon cycle components: NPP and fire risk. Environ Res Commun. https://doi.org/10.1088/2515-7620/ab8b29

Cawson JG, Nyman P, Schunk C, et al (2020) Estimation of surface dead fine fuel moisture using automated fuel moisture sticks across a range of forests worldwide. Int J Wildl Fire. https://doi.org/10.1071/WF19061

Chen DK, Zhou XF, Zhao HX, et al (1982) Study on the structure, function and succession of the four types in natural secondary forest. J Northeast For Univ 10:1-20

Chuvieco CE, Aguado I, Cocero D, et al (1999) Remote Sensing of Large Wildfires

Chuvieco E, Riaño D, Aguado I, Cocero D (2002) Estimation of fuel moisture content from multitemporal analysis of Landsat Thematic Mapper reflectance data: Applications in fire danger assessment. Int J Remote Sens 23:2145-2162. https://doi.org/10.1080/01431160110069818

De Groot WJ, Groot WJ De (1987) Interpreting the Canadian Forest Fire Weather Index (FWI) System. Fourth Cent Reg Fire Weather Comm Sci Tech Semin Proceeding:3-14. https://doi.org/citeulike-article-id:14176512

De Jong MC, Wooster MJ, Kitchen K, et al (2016) Calibration and evaluation of the Canadian Forest Fire Weather Index (FWI) System for improved wildland fire danger rating in the United Kingdom. Nat Hazards Earth Syst Sci 16:1217-1237. https://doi.org/10.5194/nhess-16-1217-2016

De Melo-Abreu JP, Daldoum MA, Andrews PL, et al (2010) Applications of meteorology to forestry and non-forest trees. Geneva WMO Guid to Agric Meteorol Pract

Di Giuseppe F, Pappenberger F, Wetterhall F, et al (2016) The potential predictability of fire danger provided by numerical weather prediction. J Appl Meteorol Climatol 55:2469-2491. https://doi.org/10.1175/JAMC-D-15-0297.1

Dimitrakopoulos AP, Bemmerzouk AM, Mitsopoulos ID (2011) Evaluation of the Canadian fire weather index system in an eastern Mediterranean environment. Meteorol Appl 18:83-93. https://doi.org/10.1002/met.214 
Dimitrakopoulos AP, Papaioannou KK (2001) Flammability assessment of Mediterranean forest fuels. Fire Technol 37:143-152. https://doi.org/10.1023/A:1011641601076

Dowdy AJ, Mills GA, Finkele K, de Groot W (2010) Index sensitivity analysis applied to the Canadian Forest Fire Weather Index and the McArthur Forest Fire Danger Index. Meteorol Appl 17:298-312. https://doi.org/10.1002/met.170

Estes BL, Knapp EE, Skinner CN, Uzoh FCC (2012) Seasonal variation in surface fuel moisture between unthinned and thinned mixed conifer forest, northern California, USA. Int J Wildl Fire 21:428-435. https://doi.org/10.1071/WF11056

Fernandes PM (2019) Variation in the canadian fire weather index thresholds for increasingly larger fires in Portugal. Forests 10:. https://doi.org/10.3390/f10100838

Field RD (2020) Evaluation of Global Fire Weather Database reanalysis and short-term forecast products. Nat Hazards Earth Syst Sci 20:1123-1147. https://doi.org/10.5194/nhess-20-1123-2020

Field RD, Spessa AC, Aziz NA, et al (2015) Development of a Global Fire Weather Database. Nat Hazards Earth Syst Sci 15:1407-1423. https://doi.org/10.5194/nhess-15-1407-2015

Flannigan MD, Krawchuk MA, De Groot WJ, et al (2009) Implications of changing climate for global wildland fire. Int J Wildl Fire 18:483-507. https://doi.org/10.1071/WF08187

Flannigan MD, Logan KA, Amiro BD, et al (2005) Future area burned in Canada. Clim Change 72:1-16. https://doi.org/10.1007/s10584-005-5935-y

Fujioka FM, Gill AM, Viegas DX, Wotton BM (2008) Chapter 21 Fire Danger and Fire Behavior Modeling Systems in Australia, Europe, and North America. Dev Environ Sci 8:471-497. https://doi.org/10.1016/S1474-8177(08)00021-1

Good P, Moriondo M, Giannakopoulos C, Bindi M (2008) The meteorological conditions associated with extreme fire risk in Italy and Greece: Relevance to climate model studies. Int J Wildl Fire 17:155-165. https://doi.org/10.1071/WF07001

Keane RE (2015) Wildland fuel fundamentals and applications. Springer

Lahaye S, Curt T, Fréjaville T, et al (2018) What are the drivers of dangerous fires in Mediterranean France? Int J Wildl Fire 27:155-163. https://doi.org/10.1071/WF17087

Li J, Song Y, Huang X, Li M (2015) Comparison of forest burned areas in mainland China derived from MCD45A1 and data recorded in yearbooks from 2001 to 2011. Int J Wildl Fire 24:103-113. https://doi.org/10.1071/WF14031

Lynham TJ, Stocks BJ (1989) Suitability of the Canadian Forest Fire Damger Rating System for use in the Daxinganling Forestry Management Bureau Heilongjiang Province, China. In: Proceedings of the 10th Conference on Fire and Forest Whitewood= Compte rendu du 10ieme Congress sur les incendies et la meterologie forestiere/editeurs DC Maiver, H. Auld, R. Whitewood. Ottawa, Ont.? Forestry Canada 1989.

Masinda MM, Li F, Liu Q, et al (2021) Prediction model of moisture content of dead fine fuel in forest plantations on Maoer Mountain, Northeast China. J For Res 1-13

Masinda MM, Sun L, Wang G, Hu T (2020) Moisture content thresholds for ignition and rate of fire spread for various dead fuels in northeast forest ecosystems of China. J For Res. https://doi.org/10.1007/s11676-020-01162-2

Matthews S (2014) Dead fuel moisture research: 1991-2012. Int J Wildl Fire 23:78-92. https://doi.org/10.1071/WF13005

Matthews S (2010) Effect of drying temperature on fuel moisture content measurements. Int J Wildl Fire 19:800-802. https://doi.org/10.1071/WF08188

Nöchel J, Svennin JC (2017) Recent tree cover increases in eastern China linked to low, declining human pressure, steep topography, and climatic conditions favoring tree growth. PLoS One 12:. https://doi.org/10.1371/journal.pone.0177552

Papagiannaki K, Giannaros TM, Lykoudis S, et al (2020) Weather-related thresholds for wildfire danger in a Mediterranean region: The case of Greece. Agric For Meteorol 291:108076. https://doi.org/10.1016/j.agrformet.2020.108076 
Papakosta P, Straub D (2017) Probabilistic prediction of daily fire occurrence in the Mediterranean with readily available spatiotemporal data. IForest 10:32-40. https://doi.org/10.3832/ifor1686-009

Rothermel RC (1972) A mathematical model for predicting fire spread in wildland fuels. Intermountain Forest \& Range Experiment Station, Forest Service, U.S. Dept. of Agriculture

Schunk C, Wastl C, Leuchner M, Menzel A (2017) Fine fuel moisture for site- and species-specific fire danger assessment in comparison to fire danger indices. Agric For Meteorol 234-235:31-47. https://doi.org/10.1016/j.agrformet.2016.12.007

Simpson CC, Grant Pearce H, Sturman AP, Zawar-Reza P (2014) Behaviour of fire weather indices in the 2009-10 New Zealand wildland fire season. Int J Wildl Fire 23:1147-1164. https://doi.org/10.1071/WF12169

Stocks BJ, Lynham TJ, Lawson BD, et al (1989) Canadian forest fire danger rating system: an overview. For Chron 65:258-265 Thomas B (1990) The Jiagedaqi Project: forest fire control in China. For Chron 66:266-270. https://doi.org/10.5558/tfc66266-3 Tian X, McRae DJ, Jin J, et al (2011) Wildfires and the Canadian forest fire weather index system for the Daxing'anling region of China. Int J Wildl Fire 20:963-973. https://doi.org/10.1071/WF09120

Tian XR, Zhao FJ, Shu LF, Wang MY (2014) Changes in forest fire danger for south-western China in the 21st century. Int J Wildl Fire 23:185-195. https://doi.org/10.1071/WF13014

Tosic I, Mladjan D, Gavrilov MB, et al (2019) Potential influence of meteorological variables on forest fire risk in Serbia during the period 2000-2017. Open Geosci 11:414-425. https://doi.org/10.1515/geo-2019-0033

Tremblay PO, Duchesne T, Cumming SG (2018) Survival analysis and classification methods for forest fire size. PLoS One 13:1-16. https://doi.org/10.1371/journal.pone.0189860

Tsinko Y, Bakhshaii A, Johnson EA, Martin YE (2018) Comparisons of fire weather indices using Canadian raw and homogenized weather data. Agric For Meteorol 262:110-119. https://doi.org/10.1016/j.agrformet.2018.07.005

Van Wagner CE (1987) Development and structure of the Canadian forest fire weather index system

Van Wagner CE (1974) Structure of the Canadian Forest Weather Index. Dep Environ Can For Serv

Vitolo C, Di Giuseppe F, Krzeminski B, San-Miguel-ayanz J (2019) Data descriptor: A 1980-2018 global fire danger re-analysis dataset for the Canadian fire weather indices. Sci Data 6:1-10. https://doi.org/10.1038/sdata.2019.32

Wang AX, Cantin A, Parisien M, et al (2019) Package ' cffdrs '

Wang C (2006) Biomass allometric equations for 10 co-occurring tree species in Chinese temperate forests. For Ecol Manage 222:9-16. https://doi.org/10.1016/j.foreco.2005.10.074

Wotton BM (2009) Interpreting and using outputs from the Canadian Forest Fire Danger Rating System in research applications. Environ Ecol Stat 16:107-131. https://doi.org/10.1007/s10651-007-0084-2

Wu Z, He HS, Keane RE, et al (2020) Current and future patterns of forest fire occurrence in China. Int J Wildl Fire 29:104-119. https://doi.org/10.1071/WF19039

Xanthopoulos G, Roussos A, Giannakopoulos C, et al (2014) Investigation of the weather conditions leading to large forest fires in the area around Athens, Greece. Parte: http://hdl handle net/103162/34013

Yang G, Di X (2011) Adaptation of Canadian Forest Fire Weather Index system and it's application. Proc - 2011 IEEE Int Conf Comput Sci Autom Eng CSAE 2011 2:55-58. https://doi.org/10.1109/CSAE.2011.5952422

Yang G, Di XY, Zeng T, et al (2010) Prediction of area burned under climatic change scenarios: A case study in the Great Xing 'an Mountains boreal forest. J For Res 21:213-218. https://doi.org/10.1007/s11676-010-0035-x

Ying L, Han J, Du Y, Shen Z (2018) Forest fire characteristics in China: Spatial patterns and determinants with thresholds. For Ecol Manage 424:345-354. https://doi.org/10.1016/j.foreco.2018.05.020

Zhang J, Cui X, Wei R, et al (2017) Evaluating the applicability of predicting dead fine fuel moisture based on the hourly Fine 
Fuel Moisture Code in the south-eastern Great Xing'an Mountains of China. Int J Wildl Fire 26:167-175. https://doi.org/10.1071/WF16040

397 Zhang JH, Yao FM, Liu C, et al (2011) Detection, emission estimation and risk prediction of forest fires in China using satellite sensors and simulation models in the past three decades-An overview. Int J Environ Res Public Health 8:3156-3178. https://doi.org/10.3390/ijerph8083156

400 Zong X, Tian X, Wang X (2021) An optimal firebreak design for the boreal forest of China. Sci Total Environ 781:146822. $401 \quad$ https://doi.org/10.1016/j.scitotenv.2021.146822

402 Zylstra PJ (2011) Forest flammability: modelling and managing a complex system. 435. https://doi.org/10.13140/2.1.3722.0166 403 
Figures
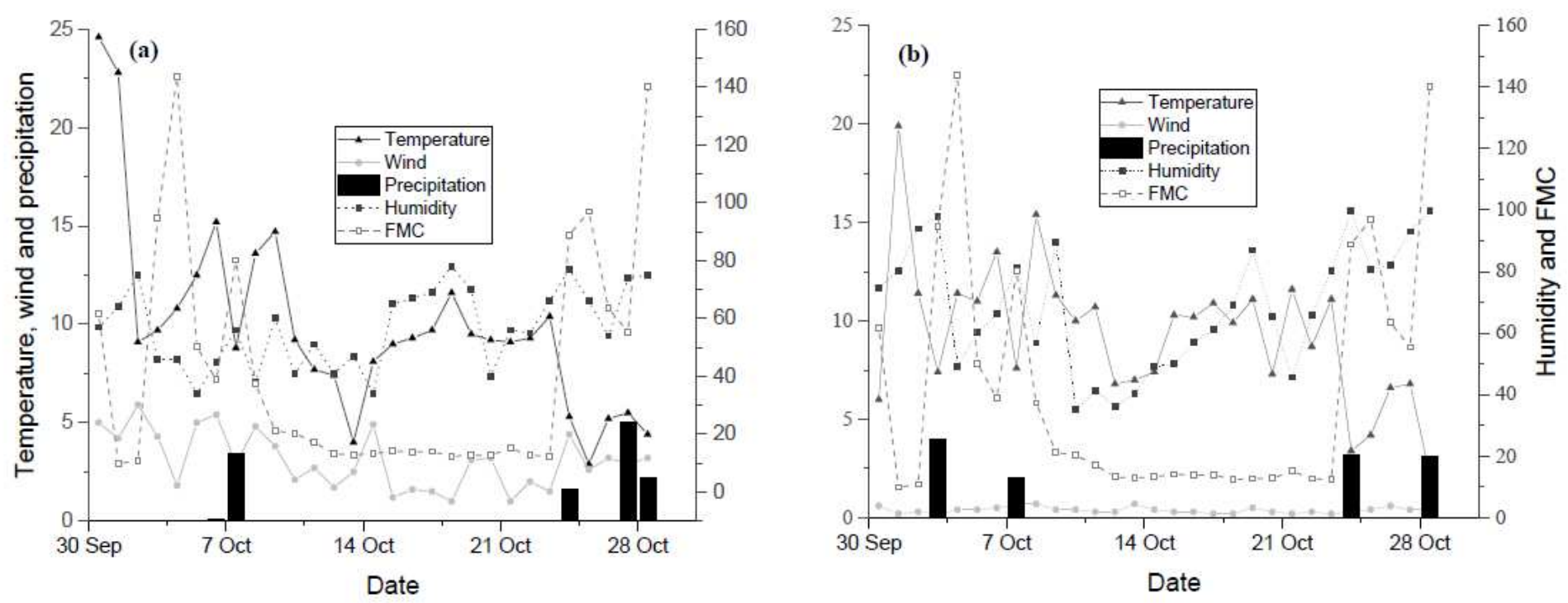

Figure 1

Variation of FMC based on (a) FMC meter and (b) China Weather Station database
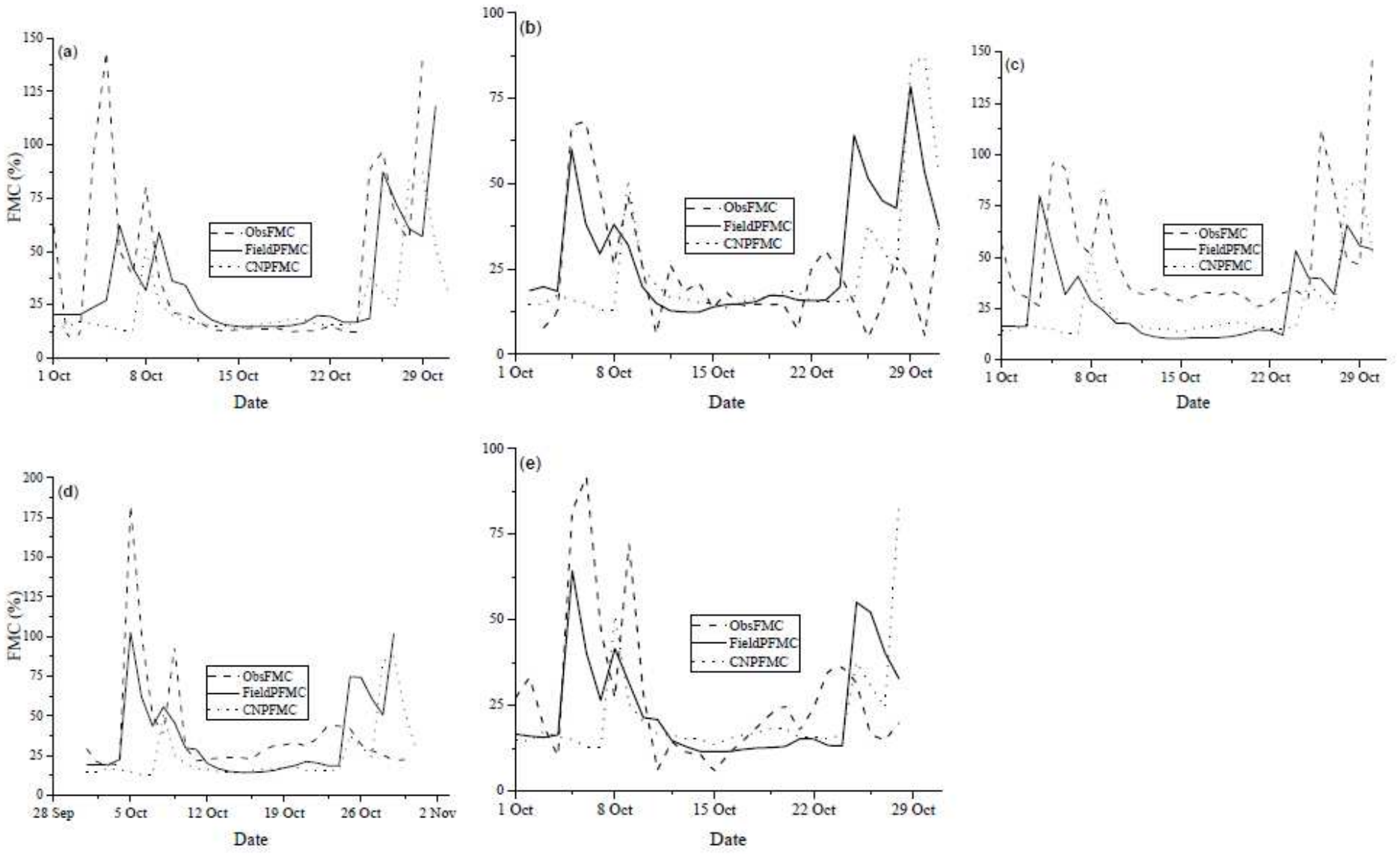

Figure 2

a, b, c, d, e Observed versus FMC meter and CWS predicted FMC, in 2019 

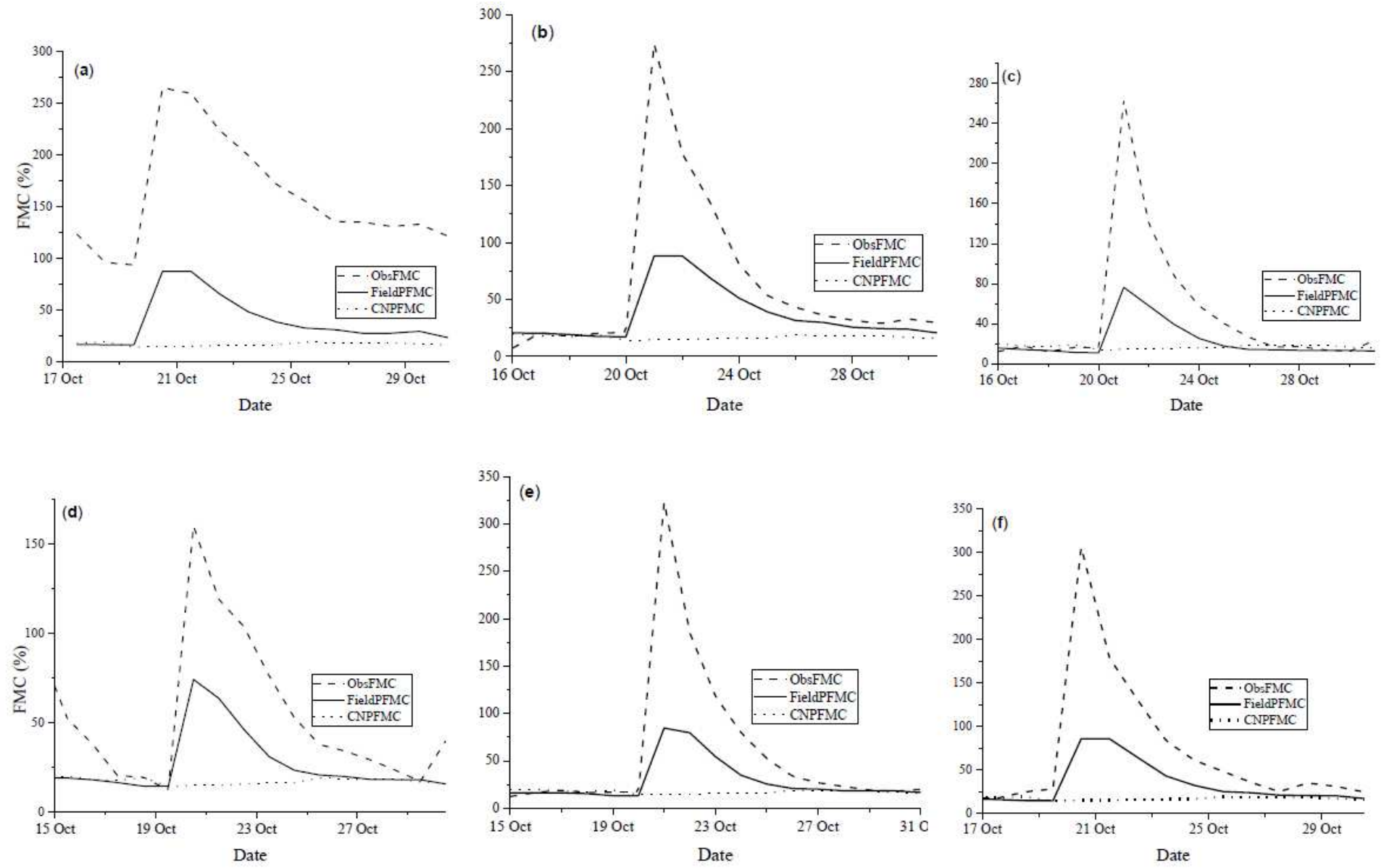

Figure 3

$a, b, c, d, e, f$ Observed versus FMC meter and CWSS predicted FMC, in 2020
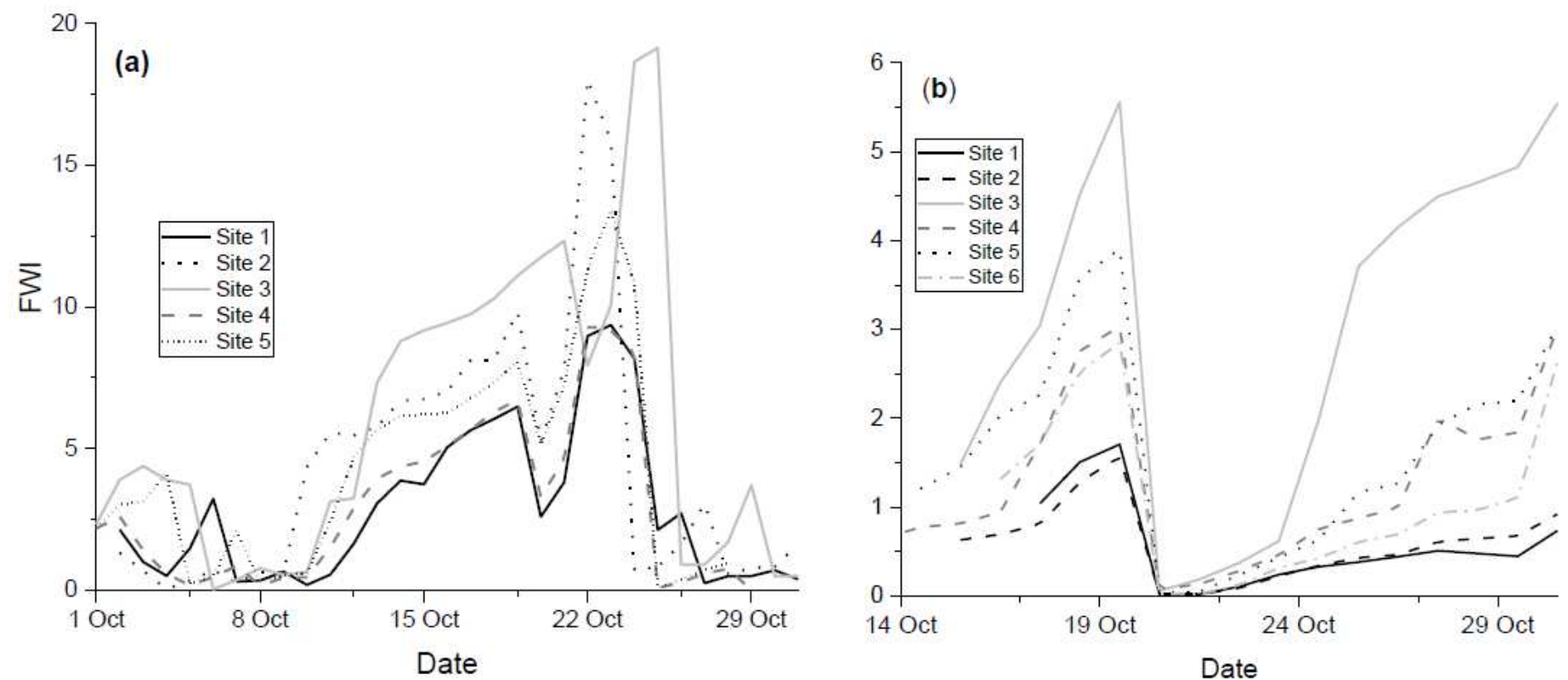

Figure 4 
Variation of FWI in 2019 (a) and 2020 (b) 